\title{
The Research of Voltage Flicker Detection Based on IRPT and Mitigation Based on BESS
}

\author{
T. Yan, Z.Z. Qu, P.Y. Jia, Y.J. Liu, J. Hu, D. Hui,X. K. Lai \\ China Electric Power Research Institute \\ Haidian District, Beijing, China
}

\begin{abstract}
This paper analysis the PCC voltage fluctuation from the perspective of active and reactive load, and points out that voltage flicker mitigation needs both active and reactive power compensation. Battery energy storage system designed by this paper adopts the current feed forward decoupling control, energy storage system after receive compensation instruction, fast response, send out a certain amount of reactive power and active power to compensate for voltage flicker.
\end{abstract}

After building the simulation models and designing the control strategy of the BESS system, this paper carries on the simulation under the environment of SIMULINK and RT-LAB. The simulation results show that the proposed method can accurately detect voltage flicker frequency and amplitude and it can effectively weaken the negative influence of imbalance of the three-phase voltage. With the active and reactive power compensation of the battery energy storage system, it can get better compensation effect of voltage flicker.

Keywords-IRPT; BESS; Voltage Flicker; Hardware-in-the-loop Simulation

\section{INTRODUCTION}

The voltage fluctuations of public connection point (PCC) are caused by irregular load variation of distribution grid. The fluctuations which have frequency between $1-10 \mathrm{~Hz}$ will cause lighting incandescent and television images flashing so that people feel fidgety. Such interference is called "flash" of "flicker" $[1,2]$. Voltage flicker can cause a decline in the efficiency of electrical equipment, torque and power oscillation, and even affect the protection system or bring great harm to power grid.

The common methods to detect voltage flicker are halfwave RMS method, square demodulation method and full wave rectification method, etc. But the effect of these methods is not ideal ${ }^{[3,4]}$. Some literature put forward application sync signal method based on wavelet multi resolution decomposition, but it needs frequency division and energy concentration of wavelet and the accurate synchronization signal so that the algorithm is not easy to achieve ${ }^{[5,6]}$. Therefore, in this paper, based on the instantaneous reactive power theory, a voltage flicker detection method combined with high precision of FFT transform is carried out to extract envelope signal of voltage flicker.

Among the compensation device of voltage flicker, due to the slow response, the effect of the traditional SVC reactive power compensation device is not ideal. In recent years the application of STATCOM voltage flicker inhibition achieved good inhibitory effect. But due to the impedance of the power distribution network is bigger, while in the compensation of reactive power, it also needs to compensate a certain amount of active power, as a result, this paper uses four quadrant operation battery energy storage devices to compensate the voltage flicker.

\section{VOLTAGE FLICKER DETECTION AND COMPENSATION METHOD}

Figure 1 shows the schematic diagram of voltage flicker detection and compensation method. Due to the voltage flicker can be equivalent to a typical low frequency modulation periodic amplitude narrowband signals. So we can get the voltage flicker envelope signal based on the instantaneous reactive power theory. Due to voltage signal may contain harmonic content, this article only acquires single-phase voltage signal, by changing the phase it can get the three-phase voltage and current signals. Then it can calculate the instantaneous active power based on the instantaneous reactive power theory. After filtering it can get the voltage signal envelope, then uses high-precision FFT to calculate flicker frequency and amplitude, and provide the basis for battery energy storage system to compensate the voltage flicker.

This paper analysis the PCC voltage fluctuation from the perspective of active and reactive load, and points out that voltage flicker mitigation needs both active and reactive power compensation. Battery energy storage system designed by this paper adopts the current feed forward decoupling control, energy storage system after receive compensation instruction, fast response, send out a certain amount of reactive power and active power to compensate for voltage flicker.

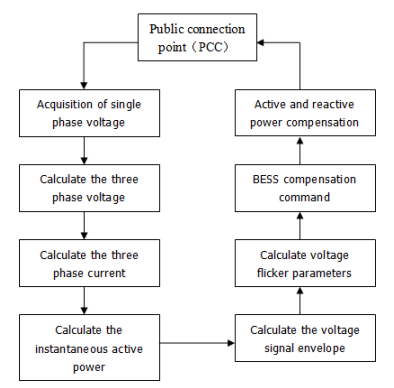

FIGURE I. THE SCHEMATIC DIAGRAM OF VOLTAGE FLICKER DETECTION AND COMPENSATION METHOD.

\section{VOLTAGE FLICKER PARAMETERS CALCULATION METHOD BASED ON IRPT}

Because of different reasons, voltage flicker can be divided into periodic and periodic flicker. This paper focuses on 
periodic flicker. The flicker can be equivalent to a lowfrequency modulation of sine voltage signal, which can be represented as:

$$
u(t)=A(t) \cos \omega t=\sqrt{2} U(1+M a(t)) \cos \omega t
$$

$\omega$ is the angular of power; $u$ is the nominal voltage ; $M$ is the frequency modulation amplitude which is $1 \%$ as common and up to $10 \% ;{ }^{A(t)}$ is the envelop signal ; ${ }^{a(t)}$ is the modulation signal, this paper uses analog modulation signal of electric arc furnace :

$$
a(t)=\sum_{m} \frac{1}{m} \cos m \Omega t
$$

$\Omega$ is the base angular of modulation signal; $m$ is the harmonic frequency.

So, flicker can be regarded as low frequency amplitude modulated narrow-band signal, using the instantaneous reactive power theory can calculate the envelope signal of voltage flicker.

(1) Calculate the three-phase voltage and three-phase current

To avoid containing harmonic voltage signal collected system, this paper only acquires single-phase voltage signal, and by proper processing it can get the three-phase voltage and current signal.

Assume $u_{a}(t)=E_{k} \sin \left(k \omega t+\phi_{k}\right)(k \geq 1)$, in the three-phase symmetric system, each phase has the same voltage waveform and phase difference of $120^{\circ}$. This paper uses voltage signal instead of current signal, which can be:

$$
\left\{\begin{array}{cc}
u_{a}(t)=u_{a}(t) & i_{a}(t)=u_{a}(t) \\
u_{b}(t)=-u_{a}(t)-u_{c}(t) & i_{b}(t)=u_{b}(t) \\
u_{c}(t)=-u_{a}\left(t-\frac{T}{6}\right) & i_{c}(t)=u_{c}(t)
\end{array}\right.
$$

(2)Calculate the instantaneous active and reactive power

Using instantaneous reactive power theory for three-phase voltage and three-phase current signal transformation, processing method in the step (1) can reduce the negative influence of three-phase unbalance. Because there is no phase difference between voltage and current signal, instantaneous reactive power is zero, so it just needs to analyze instantaneous active power.

\section{(3)Calculate voltage flicker signal envelope}

If $u_{a}(t)$ contains harmonic component, the instantaneous active power $p$ also contains harmonic component. So we need to filter the instantaneous active power, then extract the DC component to calculate voltage signal. Filter is calculated as:

$$
p^{\prime}(t)=\frac{1}{32} \sum_{k=1}^{32} p\left(t+\frac{k T}{32}\right)
$$

The voltage signal is:

$$
E(t)=\sqrt{\frac{2}{3} p^{\prime}(t)}
$$

(4)Calculate the parameters of voltage flicker

Voltage flicker envelope signal $A(t)$ contains information such as the amplitude and frequency of flicker, and therefore the parameters of voltage flicker can be calculated with the precision of FFT transformation. High precision add window interpolation FFT algorithm can effectively suppress harmonic interference and noise, and then we can precisely calculate voltage flicker parameters such as amplitude and frequency.

\section{The Voltage Flicker COMPENSATION BASED ON BESS}

In the power distribution and transmission system, we generally use the SVC and STATCOM equipment for fast reactive power compensation to improve the power quality problems of the power grid. However, the voltage flicker problem caused by the nonlinear load volatility in the distribution network is different. In order to suppress the voltage flicker more effectively, in addition to the control of reactive power compensation device, we still need to provide active power control and support.

The power absorbed by the load can be decomposed into two components: constant power $\left(P_{0}, Q_{0}\right)$ and wave power $(\Delta P, \Delta Q)$. In order to solve the voltage flicker problems caused by this type of load in distribution gird, the ideal way is to bring compensator to compensate $Q_{0}, \Delta P$ and ${ }^{\Delta Q}$. The power supply and the power factor is 1 , so that the PCC voltage amplitude and the phase are constant, as the purpose of voltage flicker compensation. Although because of the loss and the influence of other factors, $Q_{0} 、 \Delta P$ and $\Delta Q_{\text {can not achieve full }}$ compensation, but that will also bring more ideal effect of voltage flicker compensation.

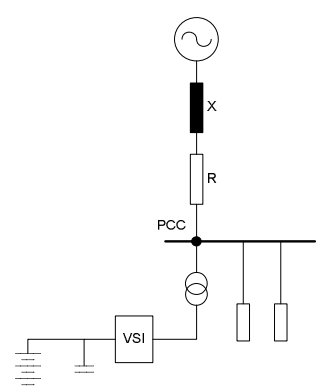

FIGURE II. INVERTER AND BATTERY ENERGY STORAGE SYSTEM SCHEMATIC DIAGRAM.

Battery energy storage system can realize four quadrant operations; it can absorb and emit active power, and also can compensate the reactive power to meet the needs of the active power and reactive power control and compensation at the 
same time. Therefore, inverter and battery energy storage system can effectively compensate the voltage flicker caused by the volatility of loads in distribution network such as electric arc furnace, and the effect is better than a single reactive compensation. Inverter and battery energy storage system schematic diagram is shown in figure 2 ; the access point is the public connection point.

\section{Voltage Flicker SUPPRESSION OF SimUlation}

\section{A. The Model of the Nonlinear Fluctuation Load}

In order to study the influence of fluctuating loads on power system, such as arc furnace and resistance welding machine. There are many methods to establish model to represent the characteristics of the fluctuating load. This paper chooses time-varying current source model to represent the load. The main part of the model is the three phase controlled power source The current amplitude satisfies the following formula:

$$
A m p=\operatorname{NomAmp}+\operatorname{ModAmp} * \sin \left(2 \pi f_{\bmod } t\right)
$$

$A m p$ is the current amplitude; NomAmp is the Rating current amplitude; ModAmp is the amplitude of the adjustment component of the current amplitude, $f_{\text {mod }}$ is the adjustment frequency. In the fluctuating load model, NomAmp is equal to $3000 * \sqrt{2} \mathrm{~A}$, ModAmp is equal to $2000 * \sqrt{2} \mathrm{~A}, f_{\text {mod }}$ is equal to $5 \mathrm{~Hz}$, the effective value of the terminal line voltage is $600 \mathrm{~V}$, so the apparent power changes between 1 MVA and 5.2MVAand the frequency is $5 \mathrm{~Hz}$, and the power factor is 0.9 .

\section{B. The Model of Inverter and Battery}

The control method of the inverter is double closed-loop control. Inner loop is current loop, the control strategy is feedforward decoupling control; Outer loop is the active and reactive current expectations.

In the simulation experiments, the rated power of the inverter is $3 \mathrm{MW}$; the rated line voltage is $380 \mathrm{~V}$.The energy storage battery model is lithium-ion battery and the rated voltage is $2200 \mathrm{~V}$, the capacity is $3 \mathrm{MAh}$. Figure 3 shows the simulation model of inverter and battery for voltage flicker compensation. Among them, the Variable Load subsystem is fluctuating loads such as arc furnace, resistance welding machine; VSI + Battery subsystem is inverter, storage Battery and its model of the control system.

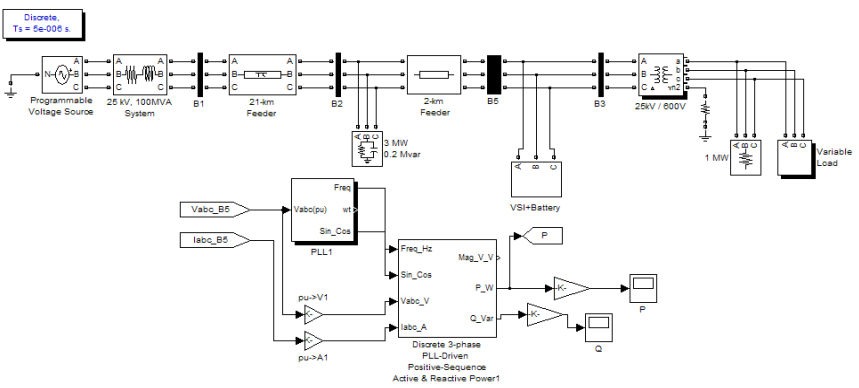

FIGURE III. THE SIMULATION MODEL OF VOLTAGE FLICKER SUPPRESSION.
This paper uses hardware-in-the-loop simulation platform RT-LAB to carry on the simulation. The distribution network, fluctuating load, inverter and main circuit components such as the energy storage battery are simulated in the RT-LAB. The inverter control part is simulated by the inverter embedded controller. The principle diagram of the simulation is shown in figure 4.

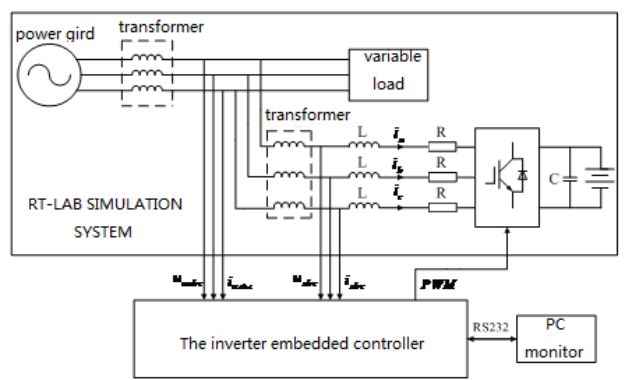

FIGURE IV. THE HARDWARE-IN-THE-LOOP SIMULATION SCHEMATIC DIAGRAM.

\section{The Simulation Results}

The load volatility action time of the experiment isfrom $7 \mathrm{~s}$ to $11 \mathrm{~s}$, fluctuating load modulation frequency is set to $2 \mathrm{~Hz}$ in the experiment. The simulation result is shown in figure 5. Compared with the case of only reactive power compensation, the effect of voltage flicker suppression has greatly improved with active and reactive power compensation at the same time.

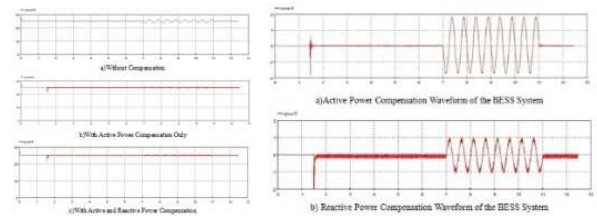

FIGURE V. THE SIMULATION RESULTFIGURE 6THE WAVEFORM OF THE COMPENSATED POWER

The figure 6 shows the waveform of the active and reactive power compensated by the BESS system. In figure a), y coordinate is the active power and the unit is MW, as on behalf of battery energy storage system to absorb. In figureb), $y$ coordinate is the reactive power and the unit is MVar; as representing a perceptual reactive power battery energy storage system. We can see from the experiment waveform that the inverter control strategy of voltage flicker suppression controller designed by this paper can realize the bidirectional converter control, so as to make the battery energy storage system to compensate active and reactive power for power distribution network at the same time for voltage flicker compensation, and the inhibition effect is more ideal.

\section{CONCLUSION}

This paper presents the voltage flicker detection method based on IRPT and compensation method based on the BESS system, and then designs the control strategy of the inverter to compensate active and reactive power. This paper uses SIMULINK to build the model of distribution network, fluctuating load and battery energy storage system, and then uses SIMULINK and RT - LAB to carry on the simulation. The simulation results show that the proposed method can 
accurately detect voltage flicker's frequency and amplitude, and it can effectively weaken the influence of three-phase voltage imbalance. By using battery energy storage system to compensate active and reactive power, it can get better voltage flicker compensation effect.

\section{ACKNOWLEDGEMENTS}

This work was supported in part by the China State Grid Corp research project" Energy storage system grid connected/off characteristics and detection technology study".

\section{REFERENCES}

[1] Application of multire solution signal decomposition formonitoring short2duration variations in dist ributi onsystems [J]. IEEE Trans Power Delivery, 2000, 15(2):478-485.

[2] Karimi M, Mkhtari H, Iravani R. Wavelet based on Line disturbance detection for power quality applications[J]. IEEE Trans Power Delivery, 2000, 15(4):12-1220

[3] T YAN, Z.Z QU, X.L ZHANG, SHINICHI KOBAYASHI,YE

ZHIYang ,Research on Designation and Control System of A-NPC Three-Level Battery Power Storage Converter[J] : Advanced Materials Research, 2014: vol.827,3120-3128, 2014.

[4] MahmoodJoorabian, Davar Mirabbasi. Voltage Flicker Compensation using STATCOM[A]. 4th IEEE Conference on Industrial Electronics and Applications, 2009: 2273-2278

[5] Zhang Li, Liu Yilu, EAF Voltage Flicker Mitigation By FACTS/ESS[A]. Power Systems Conference and Exposition[C], 2004: 372-378

[6] T YAN, Z.Z QU, D HUI, ,The business optimization analysis of the virtual power plant based on the large-scale BESS system[J] : Advanced Materials Research , 2015: vol.1071 (2015) pp 1524-1533

[7] Virulkar V. , Aware M. . Analysis of DSTATCOM with BESS for Mitigation of Flicker[A]. International Conference on Control, Automation, Communication and Energy Conservation[C], INCACEC, 2009: 1-7 